\title{
Comparison of two humidification systems for long-term noninvasive mechanical ventilation
}

\author{
S. Nava*, S. Cirio*, F. Fanfulla*, A. Carlucci*, A. Navarra\#, A. Negri" and P. Ceriana*
}

ABSTRACT: There is no consensus concerning the best system of humidification during longterm noninvasive mechanical ventilation (NIMV).

In a technical pilot randomised crossover 12-month study, 16 patients with stable chronic hypercapnic respiratory failure received either heated humidification or heat and moisture exchanger. Compliance with long-term NIMV, airway symptoms, side-effects and number of severe acute pulmonary exacerbations requiring hospitalisation were recorded.

Two patients died. Intention-to-treat statistical analysis was performed on 14 patients. No significant differences were observed in compliance with long-term NIMV, but 10 out of 14 patients decided to continue long-term NIMV with heated humidification at the end of the trial. The incidence of side-effects, except for dry throat (significantly more often present using heat and moisture exchanger), hospitalisations and pneumonia were not significantly different.

In the present pilot study, the use heated humidification and heat and moisture exchanger showed similar tolerance and side-effects, but a higher number of patients decided to continue long-term noninvasive mechanical ventilation with heated humidification. Further larger studies are required in order to confirm these findings.

KEYWORDS: Chronic obstructive pulmonary disease, humidification, noninvasive ventilation, randomised trial, restrictive thoracic disease

$\mathrm{n}$ stable hypercapnic subjects, the use of noninvasive mechanical ventilation (NIMV) can improve daytime arterial blood gas levels and decrease symptoms of hypoventilation [1, 2]. NIMV use may be hindered by lack of compliance with the treatment [3]. It has been shown that a large number of patients enrolled in home ventilation programmes may drop out during the first months, mainly due to skin irritation, upper airway problems or air leaks [3]. The lack of humidification may increase nasal resistance and nasal symptoms, especially in the presence of air leaks [4], and, therefore, contribute to reduced compliance with continuous positive airway pressure (CPAP) [5]. Some studies have demonstrated that use of heated humidification $(\mathrm{HH})$ compared to placebo may increase compliance with ventilation $[6,7]$, whereas the effects of cold passover humidifiers were partially investigated in a short-term study [6]. Interestingly, although the American College of Chest Physicians Consensus Conference [8] on the clinical indications for NIMV in chronic respiratory failure concluded that future studies should be devoted to strategies able to increase tolerance and compliance, no mention was made of the need to assess humidification of the inhaled air during long-term NIMV. The purpose of this randomised crossover pilot study lasting 12 months was to investigate the clinical effects of $\mathrm{HH}$ and heat and moisture exchanger (HME) during long-term NIMV in stable hypercapnic patients.

\section{METHODS}

Stable hypercapnic patients $(n=16)$, eight of whom were receiving long-term oxygen therapy and naive to NIMV, participated in the present randomised study lasting a total of 12 months, with a crossover after 6 months (table 1). $\mathrm{HH}$ (MR850; Fisher and Paykel Healthcare, Auckland, New Zealand) was set at a fixed temperature $\left(34^{\circ} \mathrm{C}\right.$ at $\mathrm{Y}$-piece) and the maximal percentage of humidity tolerated during a preliminary clinical test. The HME used was the hygroscopic and hydrophobic Hygrobac-Dar (Mallinckrodt Medical, Pleasanton, CA, USA), placed at the end of the catheter mount connected to the nasal mask.

Inclusion criteria were: clinical stability, arterial blood $\mathrm{pH}$ of $>7.35$, and arterial carbon dioxide tension $\left(\mathrm{Pa}_{1} \mathrm{CO}_{2}\right)$ of $>6.65 \mathrm{kPa}(>50 \mathrm{mmHg})$, a

\section{AFFILIATIONS}

${ }^{*}$ Respiratory Unit, and

\#Clinical Microbiology Laboratory, Scientific Institute of Pavia,

S.Maugeri Foundation Institute for Research and Care, Pavia, Italy.

CORRESPONDENCE

S. Nava

Respiratory Unit

Fondazione S.Maugeri

Via Maugeri n.10

27100 Pavia

Italy

Fax: 390382592075

E-mail: stefano.nava@fsm.it

Received:

January 022008

Accepted after revision:

March 042008

CLINICAL TRIAL

This study is registered at ClinicalTrials.gov at www.actr.

org.au/ (trial number

ACTRN12605000759695).

STATEMENT OF INTEREST

Statements of interest for S. Nava,

A. Carlucci and P. Ceriana can be found at www.erj.ersjournals.com/ misc/statements.shtml 
TABLE 1 Patient characteristics at enrolment

\begin{tabular}{|c|c|c|c|c|c|c|c|c|c|c|c|}
\hline $\begin{array}{l}\text { Patient } \\
\text { no. }\end{array}$ & Sex & $\begin{array}{l}\text { Age } \\
\text { yrs }\end{array}$ & $\begin{array}{c}\text { FEV } 1 \\
\text { L }\end{array}$ & $\begin{array}{c}\text { VC } \\
\text { L }\end{array}$ & $\begin{array}{r}\text { FEV }_{1} / \mathrm{VC} \\
\% \text { pred }\end{array}$ & $\begin{array}{c}\text { Arterial } \\
\mathrm{pH}\end{array}$ & $\begin{array}{l}{\mathrm{Pa}, \mathrm{O}_{2}} \\
\mathrm{mmHg}\end{array}$ & $\begin{array}{l}{\mathrm{Pa}, \mathrm{CO}_{2}} \\
\mathrm{mmHg}\end{array}$ & $\begin{array}{c}\mathrm{PS} \\
\mathrm{cmH}_{2} \mathrm{O}\end{array}$ & $\begin{array}{l}\text { PEEP } \\
\mathrm{cmH}_{2} \mathrm{O}\end{array}$ & Diagnosis \\
\hline 2 & M & 67 & 0.83 & 1.07 & 78 & 7.37 & 39.3 & 53.3 & 14 & 0 & Kypho. \\
\hline 3 & $\mathrm{~F}$ & 69 & 0.56 & 1.80 & 31 & 7.41 & 63.2 & 55.8 & 16 & 4 & COPD \\
\hline 6 & M & 72 & 1.06 & 2.15 & 49 & 7.37 & 63.2 & 55.7 & 18 & 4 & COPD \\
\hline 7 & $\mathrm{~F}$ & 52 & 0.68 & 0.84 & 81 & 7.41 & 68.0 & 53.6 & 14 & 0 & Kypho. \\
\hline 8 & M & 49 & 1.19 & 1.28 & 93 & 7.38 & 60.2 & 59.9 & 16 & 0 & $\begin{array}{l}\text { Diaphragm } \\
\text { paralysis }\end{array}$ \\
\hline 9 & $\mathrm{~F}$ & 77 & 0.48 & 1.04 & 46 & 7.39 & 65.1 & 54.7 & 16 & 4 & COPD \\
\hline 10 & $\mathrm{~F}$ & 63 & 0.36 & 1.07 & 34 & 7.39 & 55.6 & 59.5 & 18 & 2 & COPD \\
\hline 14 & M & 60 & 0.72 & 0.88 & 82 & 7.37 & 65.6 & 59.1 & 14 & 0 & Kypho. \\
\hline Mean $\pm S D$ & & $62.8 \pm 9.4$ & $0.73 \pm 0.28$ & $1.22 \pm 0.45$ & $64.5 \pm 25.1$ & $7.38 \pm 0.02$ & $61.3 \pm 7.6$ & $56.6 \pm 3.1$ & $15.6 \pm 1.3$ & $1.9 \pm 1.6$ & \\
\hline
\end{tabular}

FEV1: forced expiratory volume in one second; $\mathrm{VC}$ : vital capacity; \% pred: percentage of the predicted value; $\mathrm{Pa}_{1} \mathrm{O}_{2}$ : arterial oxygen tension; $\mathrm{Pa}_{1} \mathrm{CO}_{2}$ : arterial carbon dioxide tension; PS: pressure-support; PEEP: positive end-expiratory pressure; F: female; M: male; kypho. kyphoscoliosis; COPD: chronic obstructive pulmonary disease; TB: tuberculosis; NA: not available. $1 \mathrm{mmHg}=0.133 \mathrm{kPa}$.

decrease in $\mathrm{Pa}_{\mathrm{a}} \mathrm{CO}_{2}$ of $>6 \%$ during spontaneous breathing after 1 week of NIMV [9].

Exclusion criteria were: obstructive sleep apnoea as assessed using full-night polysomnography, cardiac failure, and an estimated life expectancy of $<12$ months. Patients with prior uvulopalatopharyngoplasty, severe chronic nasal disease and drugs that can potentially cause nasal mucosal drying were excluded [10]. Medical treatment was kept unmodified throughout the study period unless an exacerbation occurred. In particular, seven out of eight chronic obstructive pulmonary disease (COPD) patients were receiving $\beta_{2}$-agonists plus inhaled steroids, three anticholinergics and two methylxanthines. Only two out of eight of the restrictive patients were receiving respiratory drugs (inhaled steroids). During the late autumn, all of the patients underwent anti-flu vaccination.

The ventilator was chosen from among those owned by the specific homecare providers (four different types). NIMV was delivered with pressure-support ventilation with or without the addition of the external positive end-expiratory pressure. The titration of pressures was performed using physiological settings, as obtained by recording respiratory mechanics during pressure-support ventilation without any humidification system [11]. A back-up frequency of 12 breaths $\cdot \mathrm{min}^{-1}$ was applied to all of the patients. Of the patients, 13 out of 14 started with a nasal mask, two of whom needed to be switched to a fullface mask because of massive leaks, and the remaining patient used the full-face mask throughout due to better tolerance. Periodical scheduled changes of the circuits (every 2 weeks), masks (when needed) and HMEs (every second day) were guaranteed by the homecare providers. Oxygen therapy, when prescribed, was maintained constant throughout the trial.
The effective duration of nocturnal NIMV was assessed using the ventilator clock, hidden from patient view.

The patient's satisfaction with NIMV and with the system of humidification was monitored using an ad hoc point scale [12]. The patients were asked by one respiratory therapist to describe how satisfied they had been with the NIMV during the 6-month period, and how they liked the humidification system. This respiratory therapist was unaware of the aim of the present study and of the humidification system used.

At the end of the 12-month trial, the patients were instructed "now that you have tried both humidification systems, choose the one that you want to use at home from now on".

At study enrolment, patients were asked whether or not they experienced 12 nasal symptoms [6] on a regular basis (patients answered yes or no). They repeated this questionnaire at the time of the scheduled patient visit.

NIMV side-effects were assessed using a self-administered questionnaire, rating each effect on a 1-4 scale (0: not a problem; 1: slight problem, but did not interfere with NIMV use; 2: moderate problem, NIMV could sometimes not be used; 3: major problem, NIMV could often not be used; and 4: NIMV needed to be suspended). The side-effects were ranked using the questionnaire from [13].

From the clinical interview performed by the attending physician and the clinical diary, the rates of the following were determined: 1) pneumonia, as assessed according to the usual clinical, radiographic and laboratory criteria [14]; 2) hospitalisation due to severe pulmonary exacerbation, according to the published definition [15]; and 3) acute sinusitis. 
Data are presented as mean $\pm \mathrm{SD}$. The analysis was performed on an intention-to-treat basis. Comparison of continuous variables between the two groups was performed using one-way ANOVA. Categorical variables were analysed using the Chisquared test. A p-value of $<0.05$ was considered significant.

\section{RESULTS}

Two patients (one in each group) died prematurely. The statistical analysis was, therefore, performed on 14 patients. Overall, the patients tolerated the ventilation well, and only one patient needed to decrease the level of inspiratory support from 18 to $16 \mathrm{cmH}_{2} \mathrm{O}$ at 3 months.

As shown in table 2, the daily duration of NIMV was similar in both groups. On average, compliance with NIMV was good. No significant differences were observed between the COPD group and the restrictive thoracic disease (RTD) group, but there was a trend for the RTD group to show better compliance $\left(6.5 \pm 1.3\right.$ versus $5.8 \pm 1.7 \mathrm{~h} \cdot$ day $^{-1}$ at 6 months for RTD and COPD, respectively). The COPD group also showed a trend towards increased daily use of NIMV with $\mathrm{HH}\left(5.2 \pm 1.7 \mathrm{~h} \cdot \mathrm{day}^{-1}\right.$ at 3 months versus $5.8 \pm 1.5 \mathrm{~h} \cdot \mathrm{day}^{-1}$ at 6 months).

Tolerance scores for NIMV and for the humidification system also did not differ significantly, but 10 out of 14 patients expressed a preference to be sent home with $\mathrm{HH}$ once the present study had finished, and this achieved significance $\left(\chi^{2}=5.14 ; \mathrm{p}=0.02\right)$. The main reasons for this choice were "avoidance of dry throat" in six patients and "more natural breathing" in the remaining four.

As shown in table 2, nasal and throat symptoms were rare at enrolment and did not increase significantly during NIMV with both devices, except for dry throat, which occurred significantly more frequently than at enrolment with HME use $\left(\chi^{2}=4.09 ; \mathrm{p}=0.04\right)$. Most of the patients with dry throat at enrolment reported improvement after $\mathrm{HH}$ use and a worsening of this symptom with HME.

The frequency of pneumonia, severe pulmonary exacerbations requiring hospital admission and acute sinusitis were similar in both groups.

Arterial blood gas levels and pulmonary function test results did not change with the two humidification systems, but $\mathrm{Pa}, \mathrm{CO}_{2}$ was significantly reduced during NIMV versus basal conditions.

The prevalence of side-effects was exactly the same for both groups for the items considered (five reported elevated temperature, five presence of leaks and seven bad sleep (each out of 14)). No differences were found in the severity score of these symptoms.

\section{DISCUSSION}

The results of the present small pilot technical study show that compliance with treatment and the occurrence of infections were similar with $\mathrm{HH}$ and $\mathrm{HME}$, but patients receiving $\mathrm{HH}$ showed less dryness of the throat. Overall, at the end of the present study, the large majority of the patients declared their preference for $\mathrm{HH}$. The results of the present study call for future larger investigations focused mainly on cost-effectiveness analysis and on potential differences between RTD and COPD patients.

\begin{tabular}{|c|c|c|c|}
\hline & Basal & HH & HME \\
\hline \multicolumn{4}{|l|}{ Symptoms \% } \\
\hline Dry nose & 21 & 28 & 42 \\
\hline Runny nose & 7 & 14 & 14 \\
\hline Postural drip & 0 & 0 & 7 \\
\hline Nasal congestion & 21 & 21 & 28 \\
\hline Epistaxis & 0 & 0 & 0 \\
\hline Reduced sense of smell & 7 & 0 & 0 \\
\hline Sinus infections & 7 & 28 & 28 \\
\hline Dry throat & 14 & 36 & $50^{*}$ \\
\hline Sore throat & 7 & 7 & 14 \\
\hline Hoarse voice & 7 & 7 & 7 \\
\hline Cough & 43 & 36 & 43 \\
\hline Allergies & 0 & 0 & 0 \\
\hline \multicolumn{4}{|l|}{ Infection rate $\mathrm{n}$} \\
\hline $\begin{array}{l}\text { Hospitalisation for } \\
\text { acute exacerbation }\end{array}$ & & $0.21 \pm 0.07$ & $0.57 \pm 0.08$ \\
\hline Pneumonia & & $0.07 \pm 0.01$ & $0.14 \pm 0.04$ \\
\hline Acute sinusitis & & $0.28 \pm 0.07$ & $0.64 \pm 0.09$ \\
\hline \multicolumn{4}{|l|}{ NIMV } \\
\hline Compliance $h \cdot$ night $^{-1}$ & & $6.24 \pm 1.59$ & $5.97 \pm 1.24$ \\
\hline $\begin{array}{l}\text { Humidification system } \\
\text { tolerance } \mathrm{n}\end{array}$ & & $3.71 \pm 0.82$ & $4.00 \pm 0.68$ \\
\hline NIMV tolerance $\mathrm{n}$ & & $3.64 \pm 1.00$ & $3.57 \pm 0.85$ \\
\hline \multicolumn{4}{|l|}{$\begin{array}{l}\text { Pulmonary function } \\
\text { tests \% pred }\end{array}$} \\
\hline FEV 1 & $37.3 \pm 10.2$ & $39.2 \pm 11.6$ & $40.1 \pm 10.8$ \\
\hline FVC & $56.4 \pm 18.8$ & $59.0 \pm 16.4$ & $60.2 \pm 17.2$ \\
\hline \multicolumn{4}{|l|}{$\begin{array}{l}\text { Arterial blood gas } \\
\text { levels } \mathrm{mmHg}\end{array}$} \\
\hline $\mathrm{Pa}_{1} \mathrm{O}_{2}$ & $61.7 \pm 7.9$ & $63.7 \pm 8.1$ & $62.7 \pm 7.7$ \\
\hline $\mathrm{Pa}, \mathrm{CO}_{2}$ & $56.3 \pm 3.1$ & $51.1 \pm 4.2^{*}$ & $52.3 \pm 5.4^{*}$ \\
\hline Arterial pH & $7.38 \pm 0.01$ & $7.39 \pm 0.02$ & $7.39 \pm 0.3$ \\
\hline
\end{tabular}

Data are presented as percentages or mean \pm SD. Nasal and throat symptoms were assessed at enrolment (basal) and after 6 months' use of each humidification device (as in [6]). Infection rate, tolerance of noninvasive mechanical ventilation (NIMV) and of the humidification system, and effective duration of NIMV were recorded following use of each humidification device. Pulmonary function tests were performed and arterial blood gas levels breathing room air were assessed at enrolment (basal) and after 6 months use of each humidification device. $\mathrm{HH}$ : heated humidification; HME: heat and moisture exchanger; \% pred: percentage of the predicted value; FEV1: forced expiratory volume in one second; $\mathrm{FVC}$ : forced vital capacity; $\mathrm{Pa}_{\mathrm{a}} \mathrm{O}_{2}$ : arterial oxygen tension; $\mathrm{Pa}_{\mathrm{a}} \mathrm{CO}_{2}$ : arterial carbon dioxide tension. $1 \mathrm{mmHg}=0.133 \mathrm{kPa}$. * $\mathrm{p}<0.05$ versus basal.

No significant difference was found in the duration of use or the tolerance score between the two humidification systems. This is partly in contrast with findings reported in a previous study [6], which found enhanced compliance with treatment using $\mathrm{HH}$, and with one performed in normal subjects, showing that $\mathrm{HH}$ attenuated the adverse effects of mouth leak on effective tidal volume and nasal resistance and improved overall comfort [16]. The present results are, however, in agreement with those of MADOR et al. [13], who showed no 
improvement in daily CPAP use when $\mathrm{HH}$ was prescribed, as compared to the addition of $\mathrm{HH}$ only when patients complained of relevant upper airway side-effects.

It has also been shown that the magnitude of the increase in daily CPAP use with $\mathrm{HH}$ appears to be greatest during the first week of treatment [7], raising the possibility that the compliance difference may be short term, and this may also explain the difference between the present study, lasting for 6 months, versus that of MASsIE et al. [6], which lasted only 3 weeks. Further studies should indeed be performed in order to assess the effects of the different devices on sleep quality and architecture.

No overall differences were found in the number of side-effects due to the two humidification systems, even though the presence of nasal dryness increased significantly compared to the baseline condition in the HME group. This problem is probably due to the presence of unidirectional inspiratory nasal airflow, worsened by mouth leaks that may induce progressive drying of the nasal mucosa, which cannot recover water delivered to inspired gases during expiration [4]. Indeed, the relative humidity in the ventilator circuit with an HME is lower than under ambient conditions [17], and this is particularly true for increasing levels of inspiratory support [18]. Most of these physiological effects may be prevented by $\mathrm{HH}[4]$.

Having excluded those patients with a pre-existing chronic nasal disease, the effect of $\mathrm{HH}$ on most of the upper airways symptoms, with the exclusion of nasal dryness, has probably been minimised. Conversely, nothing is known regarding humidification efficacy over time for HME.

No significant differences were observed in pulmonary function test results and arterial blood gas levels between the groups. It has been shown that, in acute studies [19, 20] and compared to $\mathrm{HH}$, the HME may significantly increase dead space, work of breathing and carbon dioxide retention during an episode of acute respiratory failure requiring NIMV treatment, and this may also interfere with triggering functioning. Acute changes in $\mathrm{Pa}, \mathrm{CO}_{2}$ during NIMV may not predict a chronic effect, as demonstrated, for example, by HiLl et al. [21].

The present study was not designed to compare the cost of the different systems, since long-term NIMV usually continues for much longer than 6 months and one device (HME) should be changed every second day, whereas the most expensive part of $\mathrm{HH}$ (i.e. the body) should be changed every 6-8 yrs, meaning that amortisation over time should also be considered.

The present pilot technical study based, in part, on subjective preferences, with questionnaires submitted by operators, has several confounding factors, such as patients, researchers and homecare providers, but has the merit of being the first to compare two systems of humidification during long-term use of noninvasive mechanical ventilation in patients with chronic respiratory failure. The present study highlights the need for further larger randomised trials on the long-term effects of these different humidification systems on the incidence and severity of upper and lower airway infection. Indeed, the comparison between no humidification versus humidification remains to be elucidated.

\section{REFERENCES}

1 Annane D, Chevrolet JC, Chevret S, Raphael JC. Nocturnal mechanical ventilation for chronic hypoventilation in patients with neuromuscular and chest wall disorders. Cochrane Database Syst Rev 2000; 2: CD001941.

2 Meecham Jones DJ, Paul EA, Jones PW, Wedzicha JA. Nasal pressure support ventilation plus oxygen compared with oxygen therapy alone in hypercapnic COPD. Am J Respir Crit Care Med 1995; 152: 538-544.

3 Criner GJ, Brennan K, Travaline JM, Kreiner D. Efficacy and compliance with noninvasive positive pressure ventilation in patients with chronic respiratory failure. Chest 1999; 116: 667-675.

4 Richards GN, Cistulli PA, Ungar RG, Berthon-Jones M, Sullivan CE. Mouth leak with nasal continuous airways pressure increases nasal airway resistance. Am J Respir Crit Care Med 1996; 154: 182-186.

5 Bachour A, Maasilta P. Mouth breathing compromises adherence to nasal continuous positive airway pressure therapy. Chest 2004; 126: 1248-1254.

6 Massie CA, Hart RW, Peralez K, Richards GN. Effects of humidification on nasal symptoms and compliance in sleep apnea patients using continuous positive airway pressure. Chest 1999; 116: 403-408.

7 Neill AM, Wai HS, Bannan SPT, Beasley CR, Weatherall M, Campbell AJ. Humidified nasal continuous airway pressure in obstructive sleep apnea. Eur Respir J 2003; 22: 258-262.

8 Clinical indications for noninvasive positive pressure ventilation in chronic respiratory failure due to restrictive lung disease, COPD, and nocturnal hypoventilation - a consensus conference report. Chest 1999; 116: 521-534.

9 Karakurt S, Fanfulla F, Nava S. Is it safe for patients with chronic hypercapnic respiratory failure undergoing home non-invasive ventilation to discontinue ventilation briefly? Chest 2001; 119: 1379-1386.

10 Rakotonanahary D, Pelletier-Fleury N, Gagnadoux F, Fleury B. Predictive factors for the need for additional humidification during nasal continuous positive airway pressure therapy. Chest 2001; 119: 460-465.

11 Fanfulla F, Delmastro M, Berardinelli A, D'Artavilla Lupo N, Nava S. Effects of different ventilator settings on sleep and inspiratory effort in patients with neuromuscular disease. Am J Respir Crit Care Med 2005; 172: 619-624.

12 Navalesi $\mathrm{P}$, Costa $\mathrm{R}$, Ceriana $\mathrm{P}$, et al. Non-invasive ventilation in chronic obstructive pulmonary disease patients: helmet versus facial mask. Intensive Care Med 2007; 33: 74-81.

13 Mador MJ, Krauza M, Pervez A, Pierce D, Braun M. Effect of heated humidification on compliance and quality of life in patients with sleep apnea using nasal continuous positive airway pressure. Chest 2005; 128: 2151-2158.

14 Niederman MS, Mandell LA, Anzueto A, et al. Guidelines for the management of adults with community-acquired pneumonia: diagnosis, assessment of severity, antimicrobial therapy, and prevention. Am J Respir Crit Care Med 2001; 163: 1730-1754.

15 Burge S, Wedzicha JA. COPD exacerbations: definitions and classifications. Eur Respir J 2003; 21: Suppl. 41, 46s-53s.

16 Tuggey JM, Delmastro M, Elliott MW. The effect of mouth leak and humidification during nasal non-invasive ventilation. Respir Med 2007; 101: 1874-1879. 
17 Randerath WJ, Meier J, Genger H, Domanski U, Rühle KH. Efficiency of cold passover and heated humidification under continuous positive airway pressure. Eur Respir J 2002; 20: 183-186.

18 Holland AE, Denehy L, Buchan CA, Wilson JW. Efficacy of a heated passover humidifier during noninvasive ventilation: a bench study. Respir Care 2007; 52: 38-44.

19 Lellouche F, Maggiore SM, Deye N, et al. Effect of the humidification device on the work of breathing during noninvasive ventilation. Intensive Care Med 2002; 28: 1582 1589.

20 Jaber S, Chanques G, Matecki S, et al. Comparison of the effects of heat and moisture exchangers and heated humidifiers on ventilation and gas exchange during noninvasive ventilation. Intensive Care Med 2002; 28: 1590-1594.

21 Hill NS, Carlisle C, Kramer NR. Effect of a nonrebreathing exhalation valve on long-term nasal ventilation using a bilevel device. Chest 2002; 122: 84-91. 